http://www.sciforum.net/conference/wsf3

Article

\title{
Life Cycle Assessment: A Strategic Tool for Sustainable Development Decisions C. Koroneos ${ }^{1, *}$, E. Nanaki ${ }^{2}$, D. Rovas $^{1}$, M. Krokida ${ }^{3}$
}

${ }^{1}$ Unit of Environmental Science and Technology, Department of Chemical Engineering, National Technical University of Athens, 9 Heroon Polytechneiou Street, Zografou Campus, 15773 Athens, Greece

${ }^{2}$ University of Western Macedonia, Department of Mechanical Engineering, Bakola \& Sialvera, Kozani 50100, Greece

${ }^{3}$ School of Chemical Engineering, Process Analysis and Plant Design

National Technical University of Athens, 9 Heroon Polytechneiou Street, Zografou Campus, 15773 Athens, Greece

E-Mails: koroneos@ chemeng.ntua.gr, evananaki@gmail.com, drovas@ aix.meng.auth.gr, mkrok@ chemeng.ntua.gr,

* Author to whom correspondence should be addressed; Tel.: +30-210-7723085; Fax: +30-2107723285

Received: 17 September 2013 / Accepted: 31 October 2013 / Published: 01 November 2013

\begin{abstract}
Sustainable Development (SD) is a very commonly used phrase in the political agenda of all European countries and in the bussiness agenda of many corporations. SD as it has been defined my the Brundland report, is not a luxury anymore, it has become a necessity for our planet to keep its existence as we know it. It is necessary to apply various policy decision tools in order to reach the required objectives on all the three pillars of sustainable development, i.e. environment, economy, society. Life Cycle Assessment (LCA) is one of those tools necessary to make the right policy decisions concerning the environmental part of sustainable development. Since LCA takes into consideration the whole life cycle of a product, it could also be used not only as a tool but also as a way of thinking, leading to playing a very important role in strategy orientation. The development of new products, the operation of existing processes, the operation of the public and the private sectors, need LCA to reach decisions that will have a minimum or no impact to the environment. The objective of this work is to show the importance of LCA and its necessity for all policy decisions.
\end{abstract}


Keywords: Life Cycle Assessment, Sustainable Development, Decision Making

\section{Introduction}

Life Cycle Assessment is essential to sustainable consumption and production [1-2] as well as, to sustainable development, as it involves the evaluation of the environmental impacts of a product system through all stages of its life cycle. It is about going beyond the traditional focus on production site and manufacturing processes, in order to include the environmental, social, and economic impact of a product over its entire life cycle [3-5]. The main goals of life cycle assessment are to reduce a product's resource use and emissions to the environment as well as improve its socioeconomic performance throughout its life cycle. This may facilitate links between the economic, social and environmental dimensions within an organization and throughout its entire value chain. The terms of "life cycle analysis", "life cycle approach", "cradle to grave analysis" or "Ecobalance", stand for a rapidly emerging family of tools and techniques designed to help in environmental management and, longer term, in sustainable development.

The precursors of Life Cycle Assessment emerged in the late 1960s and early 1970s from concerns about limited natural resources, particularly oil. They came in the form of global modelling studies and energy audits. They were referred to as Resource and Environmental Profile Analyses (REPA) and Net Energy Analyses. Life Cycle Assessment has become a key complementary tool in policy and decision making, both in government and business [6].

Life Cycle Assessment is increasingly fundamental in the development of key environmental policies around the world. In the European Union, Life Cycle Assessment is at the heart of a growing number of policies and instruments in areas such as:

- Integrated Product Policy, the Sustainable Consumption and Production and Sustainable Industrial Policy Action Plan, Green Public Procurement, EU Ecolabel, EU Eco-Management and Audit Scheme, Ecodesign, Retail Forum [7-13].

- Waste: Life Cycle Thinking consists a term in the Waste Framework Directive, used to help determine the benefits of different prevention or management options. Life Cycle Thinking is also central to the Thematic Strategy on the prevention and recycling of waste, and the Thematic Strategy on the sustainable use of natural resources [14]

- Eco-innovation and the EU Environmental Technologies Action Plan (ETAP) [15].

The objective of this work is to show the importance of LCA and its necessity for all policy decisions.

\section{Life Cycle Assessment (LCA) - A Case Study}

The energy certification process for residential and commercial buildings has focused primarily on the energy use during the operational period of the building (use/operation phase). However, buildings require energy for the extraction of raw material, the production of construction materials and their transportation to the site and additional energy for their construction, maintenance and decommissioning. In order to understand the overall environmental impacts of the building, all life cycle stages should be inventoried (material production, manufacturing, use, and disposal). Life cycle 
Assessment (LCA) represents a comprehensive approach to examine the environmental impacts of an entire building [16].

LCA is a science-based and standardized environmental assessment methodology, which is used in several sectors. It is a powerful and internationally accepted analysis tool, which studies environmental aspects and potential impacts of a product or a service throughout its life cycle. LCA quantifies the resource use (energy, raw materials) and the wastes of the "product" evaluated, e.g. a building (fig. 1), and thereby can assess the environmental impacts associated with the production, use or disposal stage.

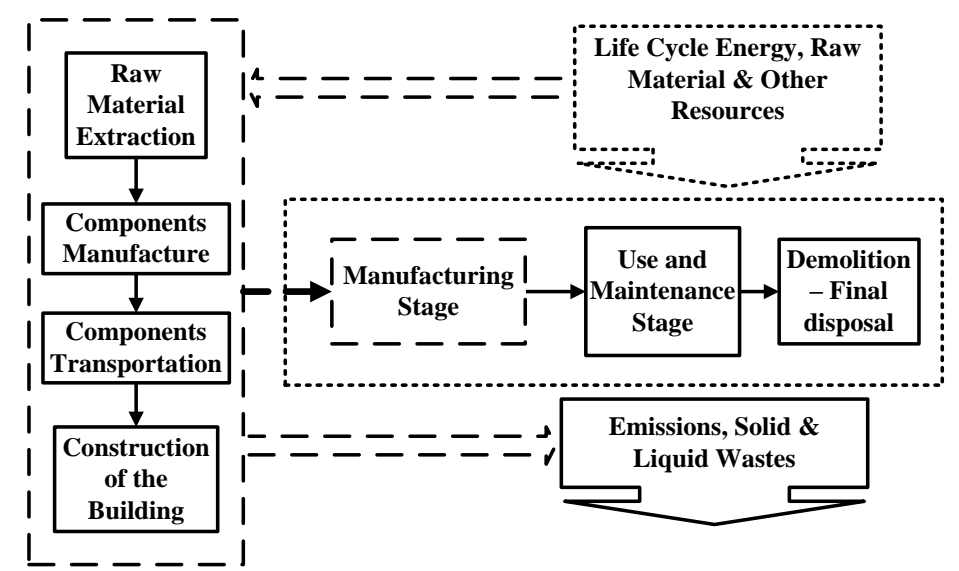

Figure 1. Life Cycle Stages of a Building

Life Cycle Assessment often refers as "Cradle-to-grave" approach, as it begins with the gathering of raw materials from the earth to create the product, the use phase of the product (mainly energy consumption) that is very much dependent on the design of the building. It ends at the point when all materials are returned to the earth (end of life management). The life cycle (fig. 1) of a building comprises of the following phases [17]:

- Raw material extraction: The building consists of various components, which are made of a large variety of materials and substances. This phase includes both the production of raw material and the use of these raw materials to produce other materials and substances. The environmental aspects and impacts from this phase arise from the mining operations, refining of ores, and manufacturing of materials and substances.

- Components manufacture: This phase covers the manufacturing of the components used in the office building, such as concrete, paint, bricks, windows etc. The components manufacture is characterised by several environmental aspects main among them being energy consumption (embodied energy) and use of materials. The role of component manufacturers is crucial to reduce the environmental impacts from this phase.

- Components transportation: Components are delivered to the construction site by road transport. The environmental impacts in this phase mainly arise from the energy consumption of the carriers.

- Construction of the office building: The main process is components placement. The main environmental aspect from this phase is the energy consumption and solid waste production of construction processes.

- Use and Maintenance stage: The use phase encompasses all activities related to the use of the building over its life. These activities include all energy consumed within the building, including heating, cooling and lighting.

- Demolition - Final Disposal/Recycle/Waste Management stage: It begins after the building has served its intended purpose and includes the demolition process and the solid waste management system (recycling and final disposal of inert materials). 
The life cycle approach takes into consideration all the energy inputs to a building in its life cycle, under the term of Life Cycle Energy. Life cycle energy (LCE) is the sum of embodied energy (EE), operation energy (OE) and demolition energy (DE) [18]:

$L C E=E E+O E+D E$

Embodied energy is the total energy used during the construction stage of a building including the energy for the excavation of raw material and the production of the buildings components, the energy used during the transportation and construction of the building but also the energy during its maintenance. It is made up of two parts; (i) the initial energy that is the energy incurred for the initial construction of the building and (ii) the recurring embodied energy, which in general corresponds to the energy during maintenance phase [18].

$\mathrm{EE}=\sum m_{i} \mathrm{E}_{i}+\mathrm{E}_{c}+\sum m_{i} \mathrm{E}_{i}\left(\left(\frac{L_{\mathrm{B}}}{L_{m_{i}}}\right)-1\right)$

Where, $\mathrm{m}_{\mathrm{i}}=$ the quantity of building material (i); $\mathrm{E}_{\mathrm{li}}=$ the energy content of material (i) per unit quantity; $\mathrm{E}_{\mathrm{ke}}=$ the energy used at site for erection/construction of the building; $\mathrm{L}_{\mathrm{B}}=$ the life span of the building; and $\mathrm{L}_{\mathrm{mi}}=$ the life span of the material (i). The operational energy OE can be expressed by [18]:

$$
\mathrm{OE}=\mathrm{OEA} L_{\mathrm{B}}
$$

Where, OEA = the annual operational energy of the building.

Finally, the DE is given by [18]:

$D E=E D+\mathrm{ET}$

Where, $\mathrm{ED}=$ the energy incurred from the destruction of the building; and ET = the transportation energy of the debris.

An overview of the existing literature has shown that $80-90 \%$ of the energy use is related to the operation phase while construction phase comprise the remaining 10-20\%. The demolition stage portion to the overall life cycle energy is negligible. Figure 2 illustrates (a) the energy use distribution of a typical office building and the (b) contribution of primary energy demand for the manufacture of the materials needed in the construction of $1 \mathrm{~m}^{2}$ (gross floor area) [19-21].

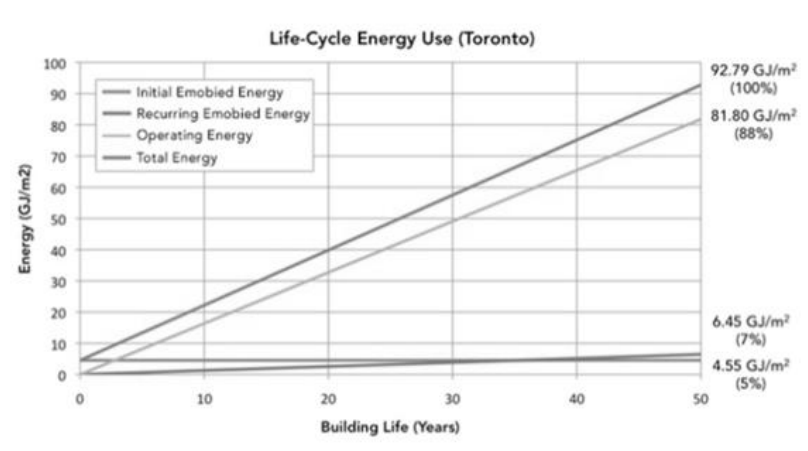

$\mathbf{a}$

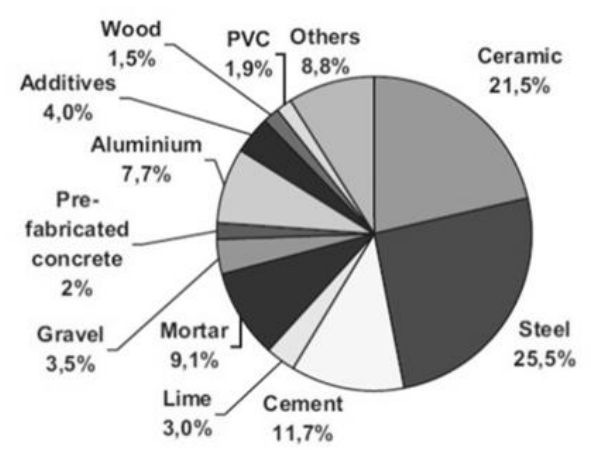

b

Figure 2. (a) Energy Use Over a 50-Year Life-Cycle for a Typical Office Building; (b) Contribution of primary energy demand for the manufacture of the materials 


\section{Impact Assessment of a Building}

The impact assessment step analyzes and evaluates the magnitude and significance of the potential environmental impacts of the life cycle of the building. The results of the inventory analysis are translated into contributions to relevant impact categories. Impact assessment consists of the classification, characterisation, normalisation and evaluation step [17].

- The classification step assigns data identified in the inventory stage to various impact categories such as abiotic depletion, acidification, eutrophication, global warming, ozone layer depletion, photochemical oxidant formation, and radioactive radiation.

- The characterisation step aims at quantifying and aggregating the potential effects, normalized to the functional unit of the product system studied. In this step the environmental interventions are quantified in terms of a common unit for that category, allowing aggregation into a single score: the indicator result. Equivalence factors are used for the different environmental effects.

- Normalization is defined as an optional element relating all impact scores of a functional unit to the impact scores of a reference situation.

- The evaluation step is the process where the impact scores of the different impact categories are compared and weighted for the comparison of the alternative products/processes. The relative importance of the impact scores is brought into perspective by normalization. In this way, impact scores are related to the total magnitude of the given impact category from all sources in a given area/period

A general review of the existing literature indicates that the phase with the highest environmental impact is the operation phase. As LCA is highly dependent on the primary energy sources, the quantity and the quality of the energy use affects the buildings environmental impact. The results of an environmental impact study performed on the construction and use phase of an office building is shown in Figure 3 [17].

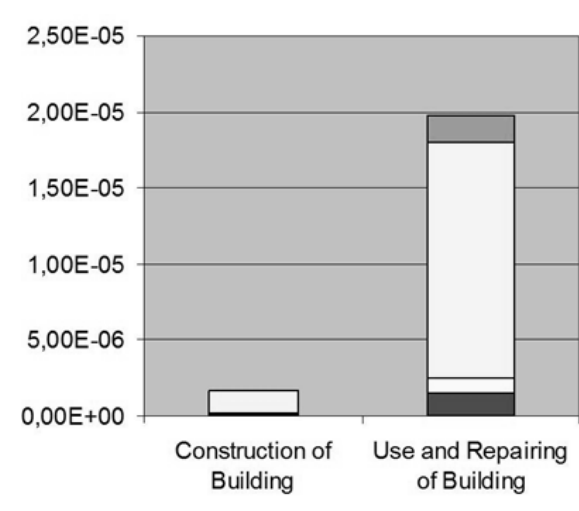

a

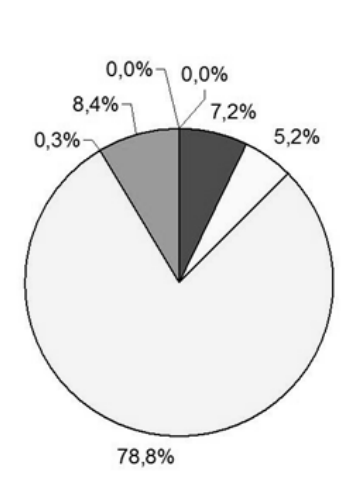

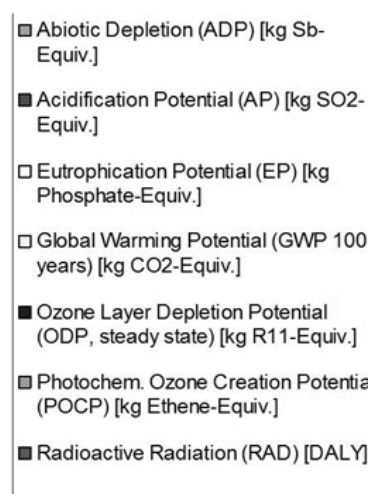

b

Figure 3 - (a) Total impact of the construction and use phase of the office building; (b) Percentage contribution of each impact category to the total impact of the office building

Not surprisingly, the use and repairing stage is significantly high for the environmental impacts of the office building life cycle. The use phase contributes by $91.94 \%$ to the total of the life cycle. The construction phase contributes by $8.06 \%$ to the total environmental score. The global warming potential is the environmental impact with the largest contribution to the overall score. GWP contributes by $83.53 \%$ to the construction phase and by $78.35 \%$ to the use phase of the building. The contribution of GWP to the total environmental score is $78.8 \%$. 
Based on the previous analysis, the optimization of operation phase performance should be given the primary emphasis for designing to minimise life cycle environmental impacts. For example, design improvements related to the building energy losses can significantly reduce cumulative burdens. The use of renewable energy sources would also improve significantly the environmental profile of the life cycle. However, all these improvements are coming at the expense of greater material production and use. From the Life cycle analysis point of view, this does not always lead to a minimization of the life cycle energy as the reduction of the operation energy may induce an increase in embodied energy (thicker insulation, photovoltaic panel utilization). This is shown in figure 4 where the use of renewable energy after the critical point does not improves the environmental performance of the building. What LCA actually can do is to preserve that the overall cumulative energy demand (primary energy) could be the one to ensure the environmental sustainability of the building.

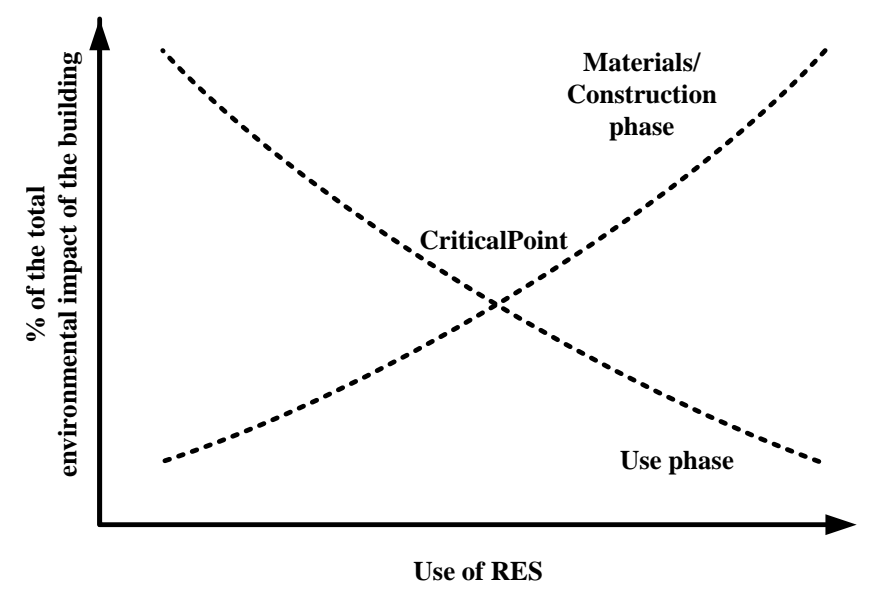

Figure 4. Impact of RES usage in the total environmental impact of the building

\section{Conclusions}

Sustainable development has been included as a major item on most governmental agendas since the 1992 Rio summit. A life cycle approach ensures that actions towards a more sustainable future will have the desired effect. LCA as a specific tool can ensure this in some cases, while LCA as an approach or as a strategic tool can give directions but not the whole answer, and must therefore be applied along with other tools such as risk assessment, environmental impacts assessment, cost-benefit analysis and others.

LCA is one of the methods increasingly being used to assess the environmental impacts, associated with the production, use and end phase (recycling, disposal) of a product or an activity. LCA can be considered as an emerging tool in the development of public policy and in design decisions, as it analyzes multiple attributes of a product or system from a cradle to grave perspective. It also has the unique ability to create a quantitative inventory listing of all process inputs and outputs, including environmental emissions and energy resources, and therefore can determine the phase/ production stage where the improvements need to be done. The implementation of LCA combined with multicriteria analysis can give a holistic picture of a system's performance and help the designer as well as all stakeholders to indentify the environmental burden and develop tools for a more sustainable living. 


\section{Conflict of Interest}

"The authors declare no conflict of interest".

\section{References and Notes}

1. Hertwich E. (2005). Life cycle approaches to sustainable consumption: a critical review. Environmental Science \& Technology 39 (13): p. 4673.

2. European Commission (2003). Towards a Thematic Strategy on the Sustainable Use of Natural Resources. Communication from the Commission to the Council and the European Parliament, Brussels, 1.10.2003.

3. UNEP, (2007) : Life Cycle Management. A business guide to sustainability".

4. UNEP (2009). Division of Technology, Industry, and Economics - Sustainable Consumption \& Production Branch official website. Retrieved from http://www.uneptie.org/scp/.

5. UNEP (2004). Why Take A Life Cycle Approach? Nairobi, Kenya: United Nations Publications.

6. Koroneos C.J.; Achillas Ch.; Moussiopoulos N.; Nanaki E.A. (2013) ." Life Cycle Thinking in the Use of Natural Resources". Journal of Open Environmental Sciences, vol. 7: 1-6.

7. Integrated Product Policy (IPP): http://ec.europa.eu/environment/ipp/

8. The Sustainable Consumption and Production and Sustainable Industrial Policy Action Plan (SCP/SIP):http://ec.europa.eu/environment/eussd/escp_en.htm

9. The Ecodesign Directive: http://ec.europa.eu/enterprise/eco_design

10. Green Public Procurement (GPP): http://ec.europa.eu/environment/gpp

11. EU Ecolabel: http://www.ecolabel.eu/

12. Eco-Management and Audit Scheme (EMAS): http://ec.europa.eu/environment/emas/about/summary_en.htm

13. Retail Forum: http://ec.europa.eu/environment/industry/retail/index_en.htm

14. Waste Framework Directive: http://ec.europa.eu/environment/waste/framework/index.htm

15. The EU Environmental Technologies Action Plan (ETAP) http://ec.europa.eu/environment/etap/

16. W.-H. Tsai, et. all 2011. Incorporating life cycle assessments into building project decisionmaking: An energy consumption and CO2 emission perspective. Energy (36) 3022-3029

17. Koroneos C. et. All. 2007. Life Cycle Assessment of An Office Buildinng in Greece. $10^{\text {th }}$ C.E.S.T., Kos Island, 5-7 September 2007, (http://www.gnest.org/cest/PROGRAM/program_FINAL-2.pdf)

18. Ramesh T., Prakash Ravi, Shukla KK. 2010. Life cycle energy analysis of buildings: An overview. Energy and Buildings 42 1592-1600

19. Canadian Sheet Steel Building Institute. http://cn-sbs.cssbi.ca/life-cycle-assessment-buildings. (Assessed on 03/05/2012)

20. Bribian Z. et al. 2009. Life cycle assessment in buildings: State-of-the-art and simplified LCA methodology as a complement for building certification. Building and Environment (44) 2510 2520 
21. Bribian Z. et al. 2011. Life cycle assessment of building materials: Comparative analysis of energy and environmental impacts and evaluation of the eco-efficiency improvement potential. Building and Environment (46) 1133-1140

(C) 2011 by the authors; licensee MDPI, Basel, Switzerland. This article is an open access article distributed under the terms and conditions of the Creative Commons Attribution license (http://creativecommons.org/licenses/by/3.0/). 